\title{
Monitoring of cerebral oxygen saturation during resuscitation in out-of-hospital cardiac arrest: a feasibility study in a physician staffed emergency medical system
}

Jens-Christian Schewe ${ }^{\dagger}$, Marcus O Thudium ${ }^{*}$, Jochen Kappler, Folkert Steinhagen, Lars Eichhorn, Felix Erdfelder, Ulrich Heister and Richard Ellerkmann

\begin{abstract}
Background: Despite recent advances in resuscitation algorithms, neurological injury after cardiac arrest due to cerebral ischemia and reperfusion is one of the reasons for poor neurological outcome. There is currently no adequate means of measuring cerebral perfusion during cardiac arrest. It was the aim of this study to investigate the feasibility of measuring near infrared spectroscopy (NIRS) as a potential surrogate parameter for cerebral perfusion in patients with out-of-hospital resuscitations in a physician-staffed emergency medical service.

Methods: An emergency physician responding to out-of-hospital emergencies was equipped with a NONIN cerebral oximetry device. Cerebral oximetry values $\left(\mathrm{rSO}_{2}\right)$ were continuously recorded during resuscitation and transport. Feasibility was defined as $>80 \%$ of total achieved recording time in relation to intended recording time.

Results: 10 patients were prospectively enrolled. In $89.8 \%$ of total recording time, $\mathrm{rSO}_{2}$ values could be recorded (213 minutes and 20 seconds), thus meeting feasibility criteria. 3 patients experienced return of spontaneous circulation (ROSC). $\mathrm{rSO}_{2}$ during manual cardiopulmonary resuscitation (CPR) was lower in patients who did not experience ROSC compared to the 3 patients with ROSC (31.6\%, \pm 7.4 versus $37.2 \% \pm 17.0)$. ROSC was associated with an increase in $\mathrm{rSO}_{2}$. Decrease of $\mathrm{rSO}_{2}$ indicated occurrence of re-arrest in 2 patients. In 2 patients a mechanical chest compression device was used. $\mathrm{rSO}_{2}$ values during mechanical compression were increased by $12.7 \%$ and $19.1 \%$ compared to manual compression.

Conclusions: NIRS monitoring is feasible during resuscitation of patients with out-of-hospital cardiac arrest and can be a useful tool during resuscitation, leading to an earlier detection of ROSC and re-arrest. Higher initial $\mathrm{SSO}_{2}$ values during CPR seem to be associated with the occurrence of ROSC. The use of mechanical chest compression devices might result in higher $\mathrm{rSO}_{2}$. These findings need to be confirmed by larger studies.
\end{abstract}

Keywords: NIRS, CPR, Cerebral oximetry, Near infrared spectroscopy, Resuscitation, Mechanical chest compression

\footnotetext{
* Correspondence: marcus.thudium@ukb.uni-bonn.de

${ }^{\dagger}$ Equal contributors

Department of Anaesthesiology, University of Bonn Medical Center,

Sigmund-Freud-Str. 25, 53105 Bonn, Germany
} 


\section{Background}

Spontaneous circulation in out of hospital cardiac arrest (OHCA) may be restored in up to $50 \%$ of patients in the presence of well-trained emergency physicians [1-4]. Despite these promising results in the treatment of OHCA, survival rates remain low.

Discharge rates of $14 \%$ and $20 \%$ are reported in these emergency medical systems (EMS) [4], and 1-year survival rates can reach up to $11 \%$ [2]. Outcome depends on professional EMS treatment including proper post resuscitation therapy and implementation of treatment strategies as published in current guidelines [5]. Lately, investigations revealed an improvement in neurological outcome in patients treated with therapeutic hypothermia following return of spontaneous circulation (ROSC) after OHCA [6]. Multiple mechanisms are discussed to be responsible for this neuroprotective effect [7]. Undoubtfully, sufficient perfusion pressure during CPR is also crucial for neurological outcome. During basic life support chest compressions (frequency and depth of compression) as well as ventilation (end-expiratory $\mathrm{CO}_{2}$ ) are poor measures to evaluate the performance of adequate resuscitation. During CPR, cerebral blood flow decreases to 20-50\% compared to normal values [8-10]. At the same time, neurological outcome and survival depend on sufficient cerebral blood flow. To date, it is impossible to provide helpful measurements to predict neurological outcome during out-of-hospital resuscitation.

Regional cerebral oximetry with near infrared spectroscopy (NIRS) has emerged as a surrogate parameter monitoring cerebral perfusion in the intraoperative and intensive care setting [11]. The method uses the effect that light in the near-infrared spectrum can penetrate the skull, thus allowing measurements of oxyhemoglobin. The absorption of light permits the measurement of oxyhemoglobin, desoxyhemoglobin, and total hemoglobin [12]. Ono et al. have revealed that decreasing intraoperative $\mathrm{rSO}_{2}$ values due to hypotension are associated with major morbidity and mortality after cardiac surgery [13]. Murkin et al. could show that intraoperative treatment of low $\mathrm{rSO}_{2}$ values resulted in decreased major organ morbidity or mortality [14]. Small clinical studies have addressed the feasibility of NIRS technology in measuring cerebral oxygen saturation in patients during CPR. These studies included in-hospital resuscitation [15-17], and out-of-hospital cardiac arrest $[18,19]$, as well as a combination of the two $[20,21]$. The authors suggest that the use of NIRS for cerebral oximetry is promising for monitoring patients with cardiac arrest. However, none of these studies focused on routine use in a physician-staffed EMS. In summary, data is still limited, but available studies suggest that NIRS monitoring can provide a real-time non-invasive marker of cerebral perfusion and thus cerebral oximetry may have a role in optimising cerebral perfusion in cardiac arrest.

The aim of this study was to investigate the feasibility of NIRS monitoring in out-of-hospital cardiac arrests in a physician-staffed emergency medical service in daily routine. Cerebral oximetry $\left(\mathrm{rSO}_{2}\right)$ was measured during standard cardiopulmonary resuscitation. This included the optional use of a mechanical chest compression device, a decision left to the discretion of the emergency physician.

\section{Methods \\ Setting}

The emergency medical service (EMS) of the City of Bonn serves 320,000 residents in a service area of $141 \mathrm{~km}^{2}$, with a population density of 2,250 persons/ $\mathrm{km}^{2}$. The city reflects urban features. A total of 12 basic life support (BLS) units and 3 advanced life support (ALS) units serve ( 2 of them 24 hours/7 days and 1 only 10 hours weekdays) in a two tier system. The EMS has 84,240 BLS-unit hours/year and 19.410 ALS-unit hours/ year.

The EMS system responds to 33,600 emergency calls, increasing about 3-5\% per year, with 26,000 BLS-unit transports and 7,600 ALS unit interventions per year. In Bonn patients are admitted to 12 hospitals, all with different care levels.

The BLS units are at least staffed with one emergency medical technician (EMT) and one paramedic. The ALS units are staffed with one paramedic and one physician. Physicians on the ALS units are predominantly anaesthesiologists and have passed at least 2 years of postgraduate training as well as a special emergency training course according to regulations of the German medical academy. The incidence of CPR in the EMS of Bonn is within 45-55 CPRs/100,000 inhabitants/year.

\section{NIRS device}

The NONIN EQUANOX Model 7600 regional oximetry system (Nonin Medical, Plymouth, Minnesota, USA) is a portable 4-wavelength cerebral oximeter. It weighs approximately 900 grams, plus 180 grams for 2 sensor pods in the 2 sensor configuration. Dimensions are $305 \times 108 \times 130 \mathrm{~mm}$. Once the device is activated and a sensor is attached, it displays continuous $\mathrm{rSO}_{2}$ data in percent from 0 to 100 . Readings are sampled every 4 seconds. The monitor is equipped with a storage battery lasting for 4 hours when fully charged.

\section{Study population/data acquisition}

The study was performed from October 2012 to July 2013. One ALS unit, which is on duty from Monday until Friday from 8 a.m.- 6 p.m., was equipped with the NIRS device. Prior to the beginning of the study, 3 
physicians were trained for half an hour in the use of the device according to legal requirements. Whenever dispatched to emergencies with suspected cardiac arrest, which was the case when a lifeless person was reported, the physician carried the NIRS device to the scene. All patients age $>18$ years with non-traumatic cardiac arrest were included. Exclusion criteria were: trauma, hypothermia $<35^{\circ} \mathrm{C}$, and pregnancy.

If the inclusion criteria were met, the physician immediately initiated the NIRS monitoring at the time of beginning of ALS. One optode was attached on the patient's left forehead lateral of the midline and above the eyebrow to acquire the spectrum of the left frontal cortex. This process took less than 30 seconds and did not interrupt BLS. Time markers were set on the device for important events such as ROSC, use of mechanical compression devices, or termination of CPR. Advanced cardiac life support (ACLS) was performed according to 2010 ERC guidelines [5]. This included intubation by the emergency physician during ALS verified by direct laryngoscopy, auscultation and end-tidal $\mathrm{CO}_{2}$ measurement. Ventilator settings were adjusted according to the patient's estimated body weight. The $\mathrm{rSO}_{2}$ value on the device monitor was covered for the study, so that the resuscitation team was blinded to $\mathrm{rSO}_{2}$ readings and the process of routine resuscitation was not altered by the NIRS device. Intended recording time of $\mathrm{rSO}_{2}$ started immediately after the emergency physician arrived at the scene with initiation of ALS and ended when the patient arrived at the emergency department or when CPR was terminated and death testfied. Data was transferred onto a computer via bluetooth and data was analyzed offline on a standard Excel spreadsheet also used for descriptive statistics. We defined feasibility as percentage $(>80 \%)$ of total achieved recording time in relation to intended recording time. Data is displayed as mean \pm standard deviation if not mentioned otherwise.
The study was approved by the local ethics committee of the University of Bonn Medical Center.

\section{Results}

Ten consecutive patients ( 8 male and 2 female) were included. Mean age was $73 \pm 13$ years ranging from 50 to 90 years (see Table 1 for demographic data). Overall recording time was 237 minutes and 36 seconds. The oximetry signal was lost during 24 minutes and 16 seconds, resulting in 213 minutes and 20 seconds of clinical recording time during CPR. With $89.8 \%$ total recording time, feasibility criteria were met.

ROSC was achieved in 3 of 10 patients (30\%). Figure 1 displays data of a patient having not experienced ROSC. Initially 3 patients had ventricular fibrillation (VF) on arrival at the scene, while 7 patients were asystolic. Of the 3 patients with VF, 2 experienced ROSC. Of the 7 patients with initial asystole, 1 could be converted into a shockable rhythm and ROSC was established following defibrillation.

All 3 patients with ROSC were admitted to hospital. Of these patients, one (patient \#1) was admitted to ICU after coronary intervention but eventually showed no signs of neurological recovery. CT scans showed extensive brain damage, so that therapy was limited and the patient died on ICU (see Figure 2 for NIRS data). The second patient (patient \#5) to experience ROSC was discharged after successful coronary intervention and ICU stay without neurological impairment (Cerebral Performance Category, CPC 1, good performance). In the third patient where ROSC was achieved despite initial asystole (patient \#8), $\mathrm{rSO}_{2}$ increased slowly after ROSC was detected (Figure 3). After ROSC, spontaneous circulation could only be maintained under massive doses of vasopressors during transport into the hospital and the patient died shortly after admission. 2 patients were transported to a hospital with ongoing CPR with manual

Table 1 Demographic and NIRS data of all 10 included patients

\begin{tabular}{|c|c|c|c|c|c|c|c|}
\hline Patient & Age & Gender & Initial ECG & $\begin{array}{l}\mathrm{rSO}_{2} \text { during } \\
\text { manual CPR (\%) }\end{array}$ & $\begin{array}{l}\mathrm{rSO}_{2} \text { during mechanical } \\
\text { compression (\%) }\end{array}$ & $\mathrm{rSO}_{2}$ after ROSC (\%) & $\begin{array}{l}\mathrm{rSO}_{2} \text { after end of } \\
\text { CPR (no ROSC, \%) }\end{array}$ \\
\hline 1 & 64 & $\delta$ & VF & $35.3 \pm 6.9$ & - & $58.3 \pm 4.6$ & - \\
\hline 2 & 77 & 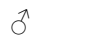 & Asy & $35.4 \pm 3.0$ & - & - & $33.1 \pm 0.9$ \\
\hline 3 & 82 & 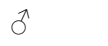 & Asy & $30.5 \pm 0.7$ & - & - & $30.9 \pm 0.3$ \\
\hline 4 & 90 & 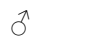 & Asy & $35.6 \pm 1.7$ & - & - & $36.0 \pm 0.4$ \\
\hline 5 & 53 & 3 & VF & $45.7 \pm 5.3$ & - & $63.2 \pm 8.0$ & - \\
\hline 6 & 76 & $\widehat{o}$ & Asy & $38.0 \pm 5.9$ & - & - & $29.3 \pm 1.4$ \\
\hline 7 & 82 & q & Asy & $18.2 \pm 3.1$ & - & - & $20.4 \pm 0.5$ \\
\hline 8 & 74 & 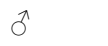 & Asy & $30.5 \pm 1.3$ & - & $35.3 \pm 4.2$ & - \\
\hline 9 & 50 & $\delta$ & VF & $37.4 \pm 4.7$ & $42.2 \pm 2.9$ & - & - \\
\hline 10 & 84 & o & Asy & $21.3 \pm 2.5$ & $25.4 \pm 2.3$ & - & - \\
\hline
\end{tabular}

Data is presented in mean \pm standard deviation. VF: ventricular fibrillation, Asy: asystole. 


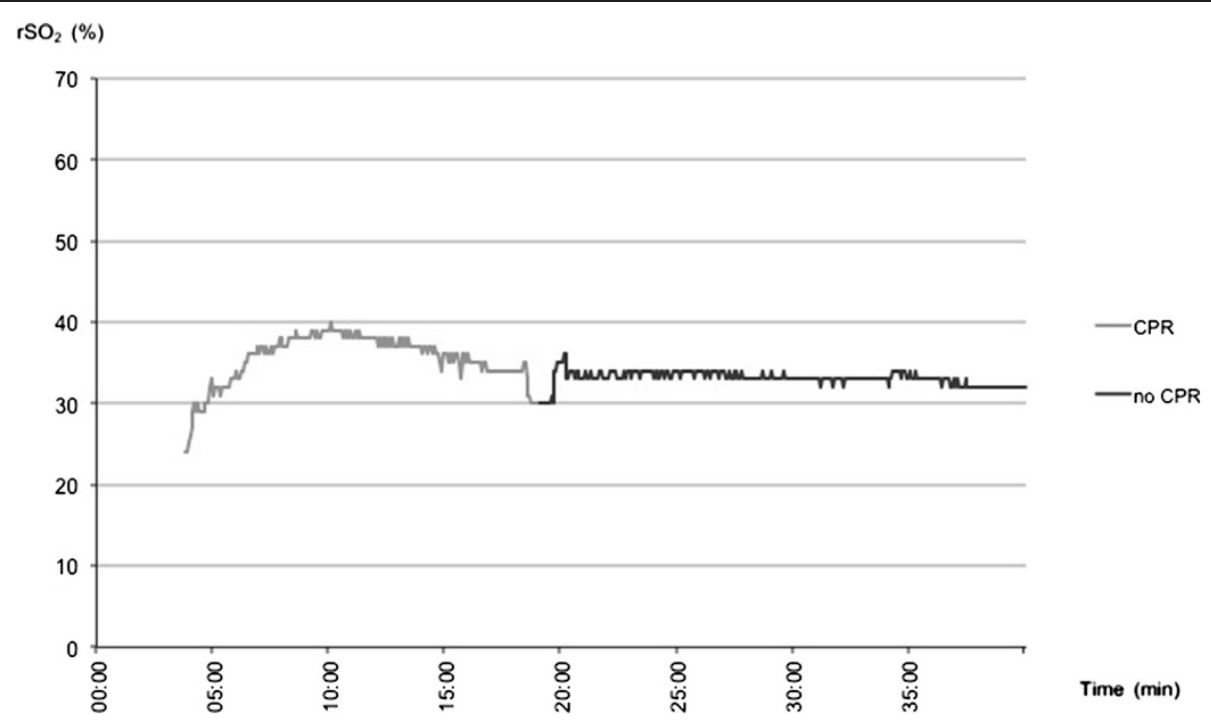

Figure 1 NIRS data of patient \#2 who never experienced ROSC.

as well as mechanical chest compressions (load distributing band CPR, AutoPulse device, ZOLL, Chelmsford, MA, USA). In both cases, CPR attempts were terminated in the emergency department of the admitting hospital, based on further examination and laboratory results by the hospital physicians. In 5 cases (50\%), resuscitation was unsuccessful and the patients died at the scene.

Mean $\mathrm{rSO}_{2}$ under manual chest compression $(\mathrm{n}=10)$ was $32.8 \% \pm 8.1$ compared to $29.9 \% \pm 5.9$ after termination of chest compressions $(n=7)$ (relative decrease in $\mathrm{rSO}_{2}$ of 8.7\%). A mechanical chest compression device was used in 2 patients. Since battery capacity of the device was limited and CPR had to be continued manually, $\mathrm{rSO}_{2}$ readings during manual and mechanical chest compression could be recorded. In one patient, mechanical compression led to a relative increase in $\mathrm{rSO}_{2}$ of $12.7 \%\left(\mathrm{rSO}_{2} 42.2 \%\right.$ vs. $\left.37.4 \%\right)$. In the second patient $\mathrm{rSO}_{2}$ during mechanical compression was $19.1 \%$ higher compared to manual compression $\left(\mathrm{rSO}_{2} 25.3 \%\right.$ vs. $21.3 \%$, see Figure 4).

In all patients with $\operatorname{ROSC}(\mathrm{n}=3)$, an increase in $\mathrm{rSO}_{2}$ was observed under spontaneous circulation. Mean $\mathrm{rSO}_{2}$ increased from $37.2 \% \pm 7.7$ before ROSC to $52.3 \% \pm 14.9$ at time of ROSC, a relative increase of $40.6 \%$.

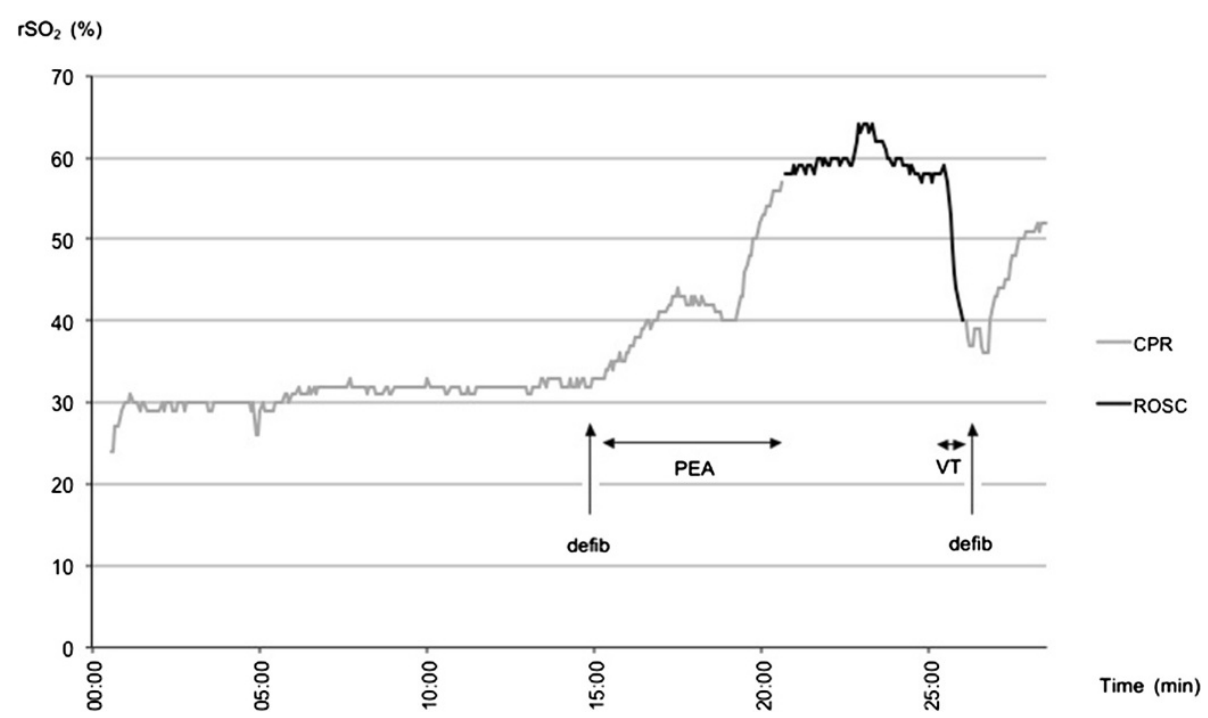

Figure 2 NIRS data of patient \#1 who had initial VF and experienced ROSC. After defibrillation and conversion into PEA there was an increase in $\mathrm{rSO}_{2}$ before $\mathrm{ROSC}$ could be diagnosed. $\mathrm{rSO}_{2}$ decreased again prior to re-arrest. 


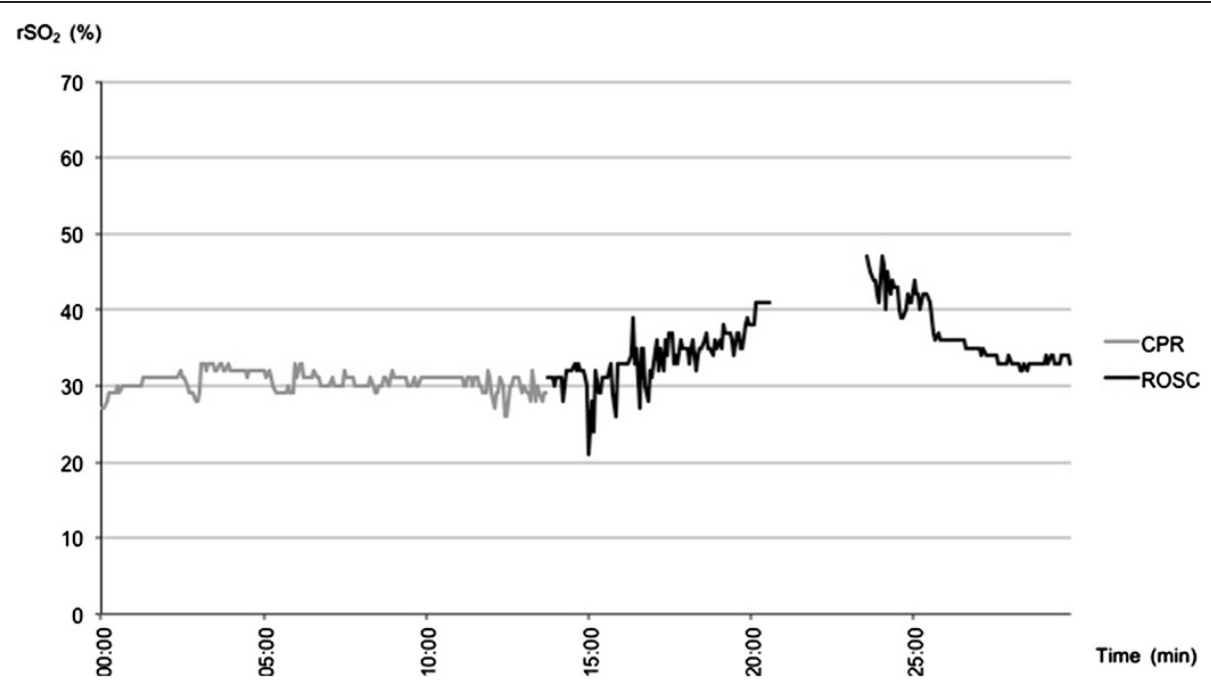

Figure 3 NIRS data of patient \#8 with ROSC after initial asystole. After ROSC $\mathrm{rSO}_{2}$ increased slowly while circulation could only be maintained with high doses of vasopressors.

Offline analysis showed that ROSC was indicated by an increase in $\mathrm{rSO}_{2}$ well before the emergency physician diagnosed ROSC through a palpable pulse in 2 patients (Figure 2). In 1 patient with initial asystole $\mathrm{rSO}_{2}$ increased after ROSC was diagnosed (Figure 3). In parallel, $\mathrm{rSO}_{2}$ decreased before the emergency physisican decided to restart CPR due to recurrent ventricular fibrillation in 2 patients (see raw data of patient 1, Figure 2).

$\mathrm{rSO}_{2}$ during CPR was lower in patients who did not experience ROSC compared to the 3 patients with ROSC $(31.6 \pm 7.4 \%$, vs. $37.2 \pm 17.0 \%$, see Figure 5).

\section{Discussion}

This study demonstrated the feasibility of $\mathrm{rSO}_{2}$ monitoring via NIRS during resuscitation in out-of-hospital cardiac arrest in a physician-staffed emergency medical system, both at the scene and also during transport of patients. Feasibility criteria for monitoring $\mathrm{rSO}_{2}$ were met by the NIRS device, providing values in $89.8 \%$ of total recording time. Moreover, a concomitant detection of increasing NIRS values in patients where ROSC was obtained and a decrease of NIRS values following rearrest with the onset of VT was observed.

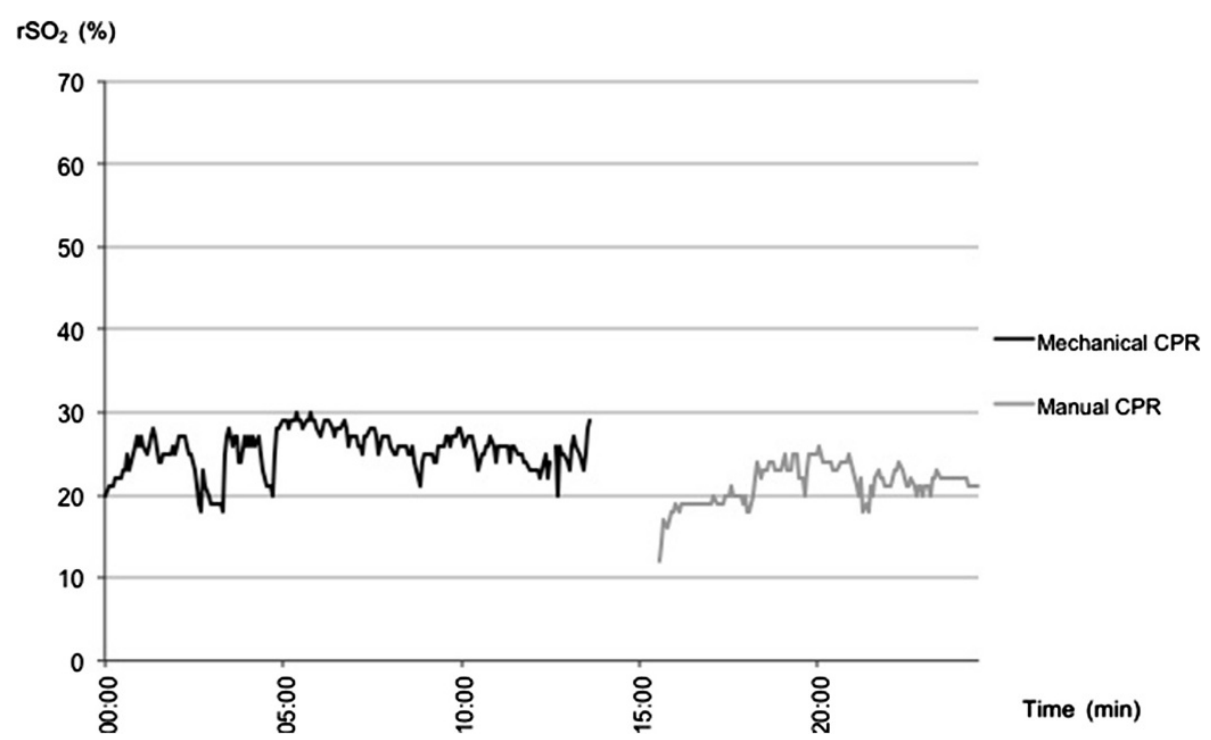

Figure 4 NIRS data of patient \#10 who never experienced ROSC. A mechanical chest compression device (load distributing band CPR) waS used for CPR. Due to limited battery capacity CPR had to be continued manually resulting in lower $\mathrm{rSO}_{2}$ values. 


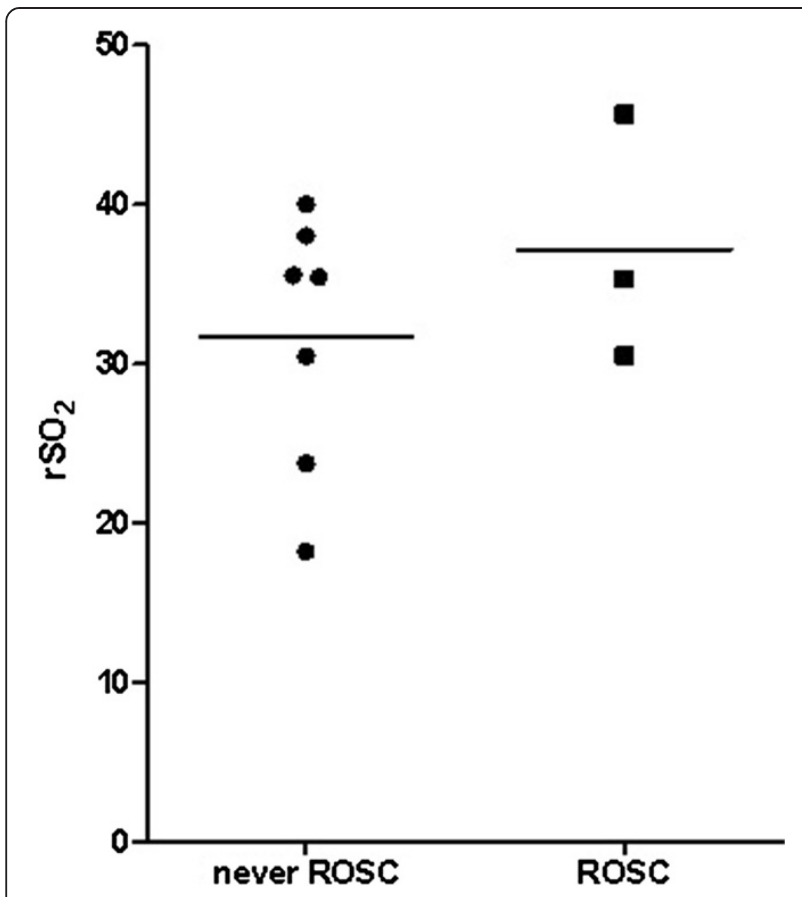

Figure 5 Scatter plot and mean $\mathrm{rSO}_{2}$ values during $\mathrm{CPR}$ of patients $(n=7)$ who never experienced ROSC and patients $(n=3)$ with ROSC.

In a different study, Newman et al. reported no detectable $\mathrm{rSO}_{2}$ signal in patients with out-of-hospital cardiac arrest [18]. Contrary to these findings, we could record stable values, possibly due to a general technological improvement in modern NIRS devices.

Only 1 out of 10 patients survived without neurological impairment (Cerebral Performance Category, CPC 1, good performance). This conforms with the general resuscitation outcome of the EMS of the City of Bonn as reported in a larger study [4]. It is remarkable that this patient had the highest $\mathrm{rSO}_{2}$ readings during CPR and ROSC $(45.7 \% \pm 5.27$ and $63.2 \%, \pm 8.02$, respectively). However, this individual finding is too limited to draw conclusions on general neurological outcome and NIRS measurements during CPR.

Ahn et al. suggested a relationship between $\mathrm{rSO}_{2}$ and ROSC as well as a relationship between low $\mathrm{rSO}_{2}$ and unsuccessful CPR [21] Koyama et al. drew similar conclusions following their results [17]. Our results are consistent with these previous findings, observing lower $\mathrm{rSO}_{2}$ readings corresponding with futile resuscitation efforts compared to $\mathrm{rSO}_{2}$ values in patients with successful $\mathrm{CPR}\left(\mathrm{rSO}_{2} 31.5 \% \pm 7.1\right.$ vs. $37.2 \% \pm 17.0$, Figure 5). The second patient to experience ROSC survived more than 24 hours, but ultimately suffered hypoxic brain damage. In this patient, ROSC was detected after a notable increase in $\mathrm{rSO}_{2}$ (35.3\%, \pm 6.94 during $\mathrm{CPR}$ vs. $58.3 \%, \pm$ 4.63 after ROSC). However, before ROSC occurred, NIRS readings showed a long period of low $\mathrm{rSO}_{2}$ (Figure 2). One could speculate $\mathrm{rSO}_{2}$ levels were low for too long and neurological damage was therefore irreversible. Unfortunately, NIRS monitoring was not continued after hospital admission. In future, the initial NIRS reading and the trend during the initial phase of resuscitation might help to predict outcome in terms of ROSC, survival and/or neurological outcome.

In the 2 patients mentioned above, $\mathrm{rSO}_{2}$ decreased before cardiac re-arrest was observed by the emergency physician. Frisch et al. published similar observations for peripheral tissue oximetry [19] and Meex et al. for cerebral oximetry [20]. We believe that NIRS could potentially improve CPR protocols by serving as an early-warning system detecting hemodynamic instability after ROSC prior to re-arrest.

In both of these patients, NIRS values increased rapidly with ROSC. In contrast, $\mathrm{rSO}_{2}$ increased slowly after ROSC in patient 8 (see Figure 3). Vasopressors had to be used to sustain circulation during transportation until therapy was finally withdrawn in the emergency department. Our study is too limited to draw assumptions between the dynamics of increase in NIRS following ROSC and stable versus unstable hemodynamics and the possible underlying pathology.

Several studies have found an increase in $\mathrm{rSO}_{2}$ after ROSC in patients [18-20]. Only Kämärainen et al. reported that $\mathrm{rSO}_{2}$ increases prior to clinical detection of ROSC [15]. It may be speculated that the time delay between increase of $\mathrm{rSO}_{2}$ in 2 cases of our study prior to documented ROSC is due to delayed clinical detection of ROSC by the physician. Guidelines recommend continuous chest compression for 2 minutes after defibrillation before analysis of cardiac rhythm and pulse. Nevertheless, within these two minutes, ROSC might be detected by increasing $\mathrm{rSO}_{2}$. In future, it may be possible to differentiate between sufficient and insufficient cerebral perfusion as detected by a significant increase in NIRS guiding the physician to continue or interrupt manual chest compression.

The use of mechanical compression devices for CPR still remains controversial. In previous studies, a higher arterial pressure and cardiac perfusion pressure were obtained with mechanical CPR devices versus manual chest compression [22,23]. A recent meta-analysis by Westfall et al. suggests the superiority of mechanical devices versus manual chest compression regarding ROSC [24]. However, there is insufficient evidence for the superiority of mechanical chest compression devices in terms of neurological outcome [25]. To our knowledge, we are the first to provide data on NIRS monitoring during mechanical and manual chest compression in OHCA. Kämärainen et al. could not show a significant increase in $\mathrm{rSO}_{2}$ by improving $\mathrm{CPR}$ with a feedback device 
(improved quality of manual chest compression) [15]. Whether this also applies to mechanical CPR devices has not been shown. In both patients where the device was applied, $\mathrm{rSO}_{2}$ values were increased by $12 \%$ and $19 \%$ compared to manual compression. This finding could support the theory that the use of mechanical CPR devices can achieve higher cerebral perfusion pressure compared to manual chest compression. However, we cannot rule out that increasing arterial $\mathrm{CO}_{2}$ might have influenced measured $\mathrm{rSO}_{2}$ values based on autoregulation of cerebral blood flow influenced by changing arterial $\mathrm{CO}_{2}$. The detected increase in measured $\mathrm{rSO}_{2}$ values during mechanical chest compressions could in theory also be explained by increasing arterial $\mathrm{CO}_{2}$ [26].

During resuscitation, end-tidal $\mathrm{CO}_{2}$ values are also used as a surrogate parameter for arterial $\mathrm{CO}_{2}$ and thus as an indirect measurement of the achieved cardiac output during $\mathrm{CPR}$. End-tidal $\mathrm{CO}_{2}$ during resuscitation is believed to be a quality marker of CPR performance [27]. In this study, end-tidal $\mathrm{CO}_{2}$ values during resuscitation were measured, but not recorded to the memory card due to technical reasons, and thus were not available for offline analysis, which limits our observational study.

\section{Conclusions}

Cerebral oximetry using NIRS for out-of-hospital cardiac arrest is feasible in a physician-staffed EMS. $\mathrm{rSO}_{2}$ monitoring can help detect ROSC and hemodynamic instabilities resulting in re-arrests. $\mathrm{rSO}_{2}$ values measured during application of a mechanical chest compression device were higher than during manual chest compression. Further investigations are needed to confirm whether these results can be explained by improved cerebral perfusion.

\section{Competing interests}

The authors declare that they have no competing interests.

\section{Authors' contributions}

JCS, MT, and RE designed the study. MT, JK, FS, LE, FE, and UH acquired and analyzed data. MT and JCS drafted the article. All authors read and approved the final manuscript.

\section{Acknowledgments}

We thank the emergency physicians and the Fire Department of the City of Bonn for their continued support.

Received: 18 January 2014 Accepted: 29 September 2014

Published online: 05 October 2014

\section{References}

1. Berdowski J, Berg RA, Tijssen JGP, Koster RW: Global incidences of out-ofhospital cardiac arrest and survival rates: Systematic review of 67 prospective studies. Resuscitation 2010, 81:1479-1487.

2. Fischer M, Fischer NJ, Schüttler J: One-year survival after out-of-hospital cardiac arrest in Bonn city: outcome report according to the "Utstein style". Resuscitation 1997, 33:233-243.

3. Herlitz J, Bahr J, Fischer M, Kuisma M, Lexow K, Thorgeirsson G: Resuscitation in Europe: a tale of five European regions. Resuscitation 1999, 41:121-131.
4. Neukamm J, Gräsner J-T, Schewe J-C, Breil M, Bahr J, Heister U, Wnent J, Bohn A, Heller G, Strickmann B, Fischer H, Kill C, Messelken M, Bein B, Lukas R, Meybohm P, Scholz J, Fischer M: The impact of response time reliability on CPR incidence and resuscitation success: a benchmark study from the German Resuscitation Registry. Crit Care Lond Engl 2011 15:R282.

5. Nolan JP, Soar J, Zideman DA, Biarent D, Bossaert LL, Deakin C, Koster RW, Wyllie J, Böttiger B, ERC Guidelines Writing Group: European Resuscitation Council Guidelines for Resuscitation 2010 Section 1: Executive summary. Resuscitation 2010, 2010(81):1219-1276.

6. Arrich J, Holzer M, Havel C, Müllner M, Herkner H: Hypothermia for neuroprotection in adults after cardiopulmonary resuscitation. Cochrane Database Syst Rev 2012, 9:CD004128.

7. Chalkias A, Xanthos T: Post-cardiac arrest brain injury: pathophysiology and treatment. J Neurol Sci 2012, 315:1-8.

8. Pernat A, Weil MH, Sun S, Tang W: Stroke volumes and end-tidal carbon dioxide generated by precordial compression during ventricular fibrillation. Crit Care Med 2003, 31:1819-1823.

9. Bartlett RL, Stewart NJ Jr, Raymond J, Anstadt GL, Martin SD: Comparative study of three methods of resuscitation: closed-chest, open-chest manual, and direct mechanical ventricular assistance. Ann Emerg Med 1984, 13(9 Pt 2):773-777.

10. Fischer M, Dahmen A, Standop J, Hagendorff A, Hoeft A, Krep H: Effects of hypertonic saline on myocardial blood flow in a porcine model of prolonged cardiac arrest. Resuscitation 2002, 54:269-280.

11. Ghosh A, Elwell C, Smith M: Review article: cerebral near-infrared spectroscopy in adults: a work in progress. Anesth Analg 2012, 115:1373-1383.

12. Moerman A, Wouters P: Near-infrared spectroscopy (NIRS) monitoring in contemporary anesthesia and critical care. Acta Anaesthesiol Belg 2010, 61:185-194.

13. Ono M, Brady K, Easley RB, Brown C, Kraut M, Gottesman RF, Hogue CW Jr: Duration and magnitude of blood pressure below cerebral autoregulation threshold during cardiopulmonary bypass is associated with major morbidity and operative mortality. J Thorac Cardiovasc Surg 2014, 147:483-489.

14. Murkin JM, Adams SJ, Novick RJ, Quantz M, Bainbridge D, Iglesias I, Cleland A, Schaefer B, Irwin B, Fox S: Monitoring brain oxygen saturation during coronary bypass surgery: a randomized, prospective study. Anesth Analg 2007, 104:51-58

15. Kämäräinen A, Sainio $M$, Olkkola KT, Huhtala $H$, Tenhunen J, Hoppu S: Quality controlled manual chest compressions and cerebral oxygenation during in-hospital cardiac arrest. Resuscitation 2012, 83:138-142.

16. Ito N, Nanto S, Nagao K, Hatanaka T, Nishiyama K, Kai T: Regional cerebral oxygen saturation on hospital arrival is a potential novel predictor of neurological outcomes at hospital discharge in patients with out-ofhospital cardiac arrest. Resuscitation 2012, 83:46-50.

17. Koyama Y, Wada T, Lohman BD, Takamatsu Y, Matsumoto J, Fujitani S, Taira $Y$ : A new method to detect cerebral blood flow waveform in synchrony with chest compression by near-infrared spectroscopy during CPR. Am J Emerg Med 2013, 31:1504-1508.

18. Newman DH, Callaway CW, Greenwald IB, Freed J: Cerebral oximetry in out-of-hospital cardiac arrest: standard CPR rarely provides detectable hemoglobin-oxygen saturation to the frontal cortex. Resuscitation 2004, 63:189-194.

19. Frisch A, Suffoletto BP, Frank R, Martin-Gill C, Menegazzi JJ: Potential utility of near-infrared spectroscopy in out-of-hospital cardiac arrest: an illustrative case series. Prehospital Emerg Care Off J Natl Assoc EMS Physicians Natl AssoC State EMS Dir 2012, 16:564-570

20. Meex I, Deyne CD, Dens J, Scheyltjens S, Lathouwers K, Boer W, Vundelinckx $G$, Heylen R, Jans F: Feasibility of absolute cerebral tissue oxygen saturation during cardiopulmonary resuscitation. Crit Care 2013, 17:R36.

21. Ahn A, Nasir A, Malik H, D'Orazi F, Parnia S: A pilot study examining the role of regional cerebral oxygen saturation monitoring as a marker of return of spontaneous circulation in shockable (VF/VT) and nonshockable (PEA/Asystole) causes of cardiac arrest. Resuscitation 2013, 84:1713-1716

22. Duchateau F-X, Gueye P, Curac S, Tubach F, Broche C, Plaisance P, Payen D, Mantz J, Ricard-Hibon A: Effect of the AutoPulse automated band chest compression device on hemodynamics in out-of-hospital cardiac arrest resuscitation. Intensive Care Med 2010, 36:1256-1260. 
23. Timerman S, Cardoso LF, Ramires JAF, Halperin H: Improved hemodynamic performance with a novel chest compression device during treatment of in-hospital cardiac arrest. Resuscitation 2004, 61:273-280.

24. Westfall M, Krantz S, Mullin C, Kaufman C: Mechanical versus manual chest compressions in Out-of-hospital cardiac arrest: a meta-analysis. Crit Care Med 2013, 41:1782-1798.

25. Ong MEH, Mackey KE, Zhang ZC, Tanaka H, Ma MH-M, Swor R, Shin SD: Mechanical CPR devices compared to manual CPR during out-of-hospital cardiac arrest and ambulance transport: a systematic review. Scand J Trauma Resusc Emerg Med 2012, 20:39.

26. Kolb JC, Ainslie PN, Ide K, Poulin MJ: Effects of five consecutive nocturnal hypoxic exposures on the cerebrovascular responses to acute hypoxia and hypercapnia in humans. J Appl Physiol Bethesda Md 1985 2004, 96:1745-1754

27. Morley PT: Monitoring the quality of cardiopulmonary resuscitation. Curr Opin Crit Care 2007, 13:261-267.

doi:10.1186/s13049-014-0058-y

Cite this article as: Schewe et al:: Monitoring of cerebral oxygen saturation during resuscitation in out-of-hospital cardiac arrest: a feasibility study in a physician staffed emergency medical system. Scandinavian Journal of Trauma, Resuscitation and Emergency Medicine $201422: 58$

\section{Submit your next manuscript to BioMed Central and take full advantage of:}

- Convenient online submission

- Thorough peer review

- No space constraints or color figure charges

- Immediate publication on acceptance

- Inclusion in PubMed, CAS, Scopus and Google Scholar

- Research which is freely available for redistribution 